\title{
The Knowledge Concealed in Users' Narratives, Valuing Clients' Experiences as Coherent Knowledge in Their Own Right
}

\author{
Ragnfrid Kogstad, ${ }^{1}$ Tor-Johan Ekeland, ${ }^{2}$ and Jan Kaare Hummelvoll ${ }^{1}$ \\ ${ }^{1}$ Hedmark University College, 2418 Elverum, Norway \\ ${ }^{2}$ Volda University College, 6101 Volda, Norway \\ Correspondence should be addressed to Ragnfrid Kogstad; ragnfrid.kogstad@hihm.no
}

Received 6 February 2014; Revised 30 April 2014; Accepted 7 May 2014; Published 28 May 2014

Academic Editor: Christine M. Blasey

Copyright (c) 2014 Ragnfrid Kogstad et al. This is an open access article distributed under the Creative Commons Attribution License, which permits unrestricted use, distribution, and reproduction in any medium, provided the original work is properly cited.

\begin{abstract}
Objective. As the history of psychiatry has been written, users have told their stories and often presented pictures incompatible with the professional or official versions. We ask if such a gap still exists and what the ethical as well as epistemological implications may be. Study Design. The design is based on a hermeneutic-phenomenological approach, with a qualitative content analysis of the narratives. Data Sources. The paper draws on user narratives written after the year 2000, describing positive and negative experiences with the mental health services. Extraction Methods. Among 972 users answering a questionnaire, 492 also answered the open questions and wrote one or two stories. We received 715 stories. 610 contained enough information to be included in this narrative analysis. Principal Findings. The stories are coherent, containing traditional narrative plots, but reports about miscommunication, rejection, lack of responsiveness, and humiliation are numerous. Conclusions. The picture drawn from this material has ethical as well as epistemological implications and motivates reflections upon theoretical and practical consequences when users' experiences do not influence professional knowledge to a larger degree.
\end{abstract}

\section{Introduction}

The stories from a subjective or patient perspective have followed the official story of psychiatry like a side stream [13]. Listening to the nonexperts, "ordinary people" or "victims of history" [4], has a long tradition in social science. Women, workers, the colonialized, religious minorities, prisoners, the ill, and also the "mad" have in turn had their voices heard. But listening to valuing and appreciating the stories of the mentally disabled has been a more complicated case and has needed more time for reasons we will return to. As expressed by Molinari [5] there has been a kind of an unequal relationship between the client who writes to express his/her truth and the professional reader who reads the story to confirm his/her diagnosis.

Even if users' perspective gradually has been set on the agenda and user involvement is established as a method for improving the health services [6-8], user involvement in the field of mental health care still does not avoid the asymmetrical relations between users and professionals, not the least because of the possibility of diagnosing users' opinions [9] rather than receiving their feedback and narratives as helpful corrections necessary in the process of improving the delivery of health services. As a consequence user involvement may be regarded only as an empowerment strategy for users and not a method by which professionals may also achieve new insights [10]. Then, necessary changes in the health services aiming at mutual collaboration may be neglected. Barker [11] holds that it is not the professionals who empower the patient; it is the person with mental illness who is in position to empower the professional. The only way to be of real service is to learn from the person. Having learned what to do for the patient, from him/her, the professionals can gain some understanding or insights, which changes them, however imperceptibly. This change in professional attitude influences the next interactions and so on (page 321).

\section{The Aim of the Study}

The study aims to analyse clients' stories written after the year 2000 and reflect upon the message in the stories as well as how 
clients experience that their stories are received and used in the process of improving the health services. Further, clients' variegated experiences and the need to communicate those experiences to leaders and professional experts are discussed from ethical and epistemological perspectives.

\section{Methodology}

The paper refers to a data material consisting of 492 users' narratives about meetings with the mental health service system [12]. The narratives were written in response to two open questions at the end of a comprehensive questionnaire: (1) Would you like to tell a story from a special meeting with a helper or a health service system that represented a turning point in your life? and (2) If you have had strong negative experiences, would you like to describe such an event?

Our methodology is anchored in a hermeneuticphenomenological tradition, focusing on individuals' subjective experiences and interpretations, where credibility depends on the coherence in the argument $[13,14]$. Further, we use elements from narrative methods in order to shed light on common narrative plots, power relations, and the implications of speaking from a nonhegemonic position [15].

Narratives can be defined in different ways, but in this paper we use the much employed definitions of Hydén [16], Edwards [17], and Mishler [18] who define narratives as stories written in a coherent way, aiming at explaining and making sense of events, legitimating actions and reactions, confirming identity, and adding meaning to experiences. Mishler [18] also maintains that the presentation and confirmation of identity is a constant factor in all personal narratives and is related to the creation of meaning. The construction of plots, understood as phrases describing a cause, an effect, and a link between them, informs the kind of meaning that is added to the experience and how cause, effect, and meaning are perceived [19].

\section{Respondents}

The data we refer to was selected from a larger study carried out in cooperation with the national user organization, Mental Health Norway (MHN). MHN was chosen because it is the largest user organization. The organization has a reasonable well-functioning relationship with the government; for example, MHN regularly serves as a consultative body and an administrative system which could assist in the collection of data. During the period of data collection, there were about 5000 members spread over the whole country. About 4000 of them, chosen randomly, were invited to take part in the study. Nearly $1 / 4$ responded. The user organization Mental Health Norway could not provide any information about the profile of their member group (like age, gender, occupation, social security support, or experiences with the help service system), but the spread we found regarding the mentioned indicators tells that the experiences are applicable for several groups of people. 492 of the respondents (151 men and 341 women, aged 19-90 years) also answered one or both of the two open questions at the end of the questionnaire. 223 of the respondents reported both a positive and a negative story, while 112 wrote only a negative story and 157 wrote only a positive story. In total we got 715 stories, some with a lot of information and others with not enough information to have them categorised in any way. The latter stories were excluded from the analysis and consequently 610 stories remained for the categorisation process. The respondents who were included in the categorisation process have experiences from all parts of the mental health care system, traditional psychiatric institutions, outpatient clinics, day centres, and individual therapy. $67 \%$ received disability pension, $13 \%$ had a job, and $20 \%$ combined disability pension with a job or studies.

The narratives were analysed by qualitative content analysis [20]. The stories were read through several times in order to discover themes embedded in the texts and to obtain a sense of the whole. Manifest content in the texts is presented as categories that may also be seen as expressions of the latent content. The presentation of meaning units in categories is based on the researcher's judgment and validated in a process where the researchers proposed categorization independently of each other.

\section{The Narratives}

In the following we present an overview of themes emerging from the stories and thereafter some example stories, chosen from all the four main categories as shown in Table 1 and which also illustrate two overriding narrative plots: the search for meaning and the confirmation of identity. Recognizing clients' stories as coherent and valuable knowledge is then discussed from ethical and epistemological perspectives.

When studying the therapeutic framework described in the stories we found-as shown in the table-two main themes: a mainly psychiatric medical approach and a humanistic-existential psychosocial approach [21]. Under each theme there were two main categories: (1) the help service experienced as being beneficial and (2) negative experiences related to rejection, humiliation, or threats. The majority of positive experiences were found where a humanistic-existential psychosocial approach was dominating and the majority of negative experiences were found in a medical context where diagnoses and medicines were the dominating means by which the clients were met.

5.1. The Creation of Meaning as a Narrative Feature. From a humanistic perspective the meaning dimension is essential to human beings $[19,22,23]$. By telling our stories we can create meaning by establishing a culture-specific sense of order, which makes life worth living [24-26]. The following stories illustrate how the mental health clients' stories display deeply human traits and deserve status as coherent knowledge in their own right and how the experience of meaning is related to (a) regaining a feeling of worth and dignity, (b) realizing that hardships can give insights and increased ability to understand and help other people, (c) discovering connections between earlier assaults and depression or anxiety, and (d) putting life experiences together in a story which can be imparted and contribute to the richness of life stories. 
TABLE 1: A summary of all the narrative themes under four main categories.

\begin{tabular}{|c|c|}
\hline Psychiatric medical approach & Humanistic-existential psychosocial approach \\
\hline $\begin{array}{l}\text { Medical-instrumental help experienced } \\
\text { as beneficial }(n=18)\end{array}$ & $\begin{array}{l}\text { Positive experiences with psychosocial and } \\
\text { social help and support }(n=297)\end{array}$ \\
\hline Beneficial medication practice & Traumas worked through \\
\hline Medicines and following up & Working through traumas \\
\hline Medicines that functioned ok & Obtained selfinsight \\
\hline Helped to reduce medicines & A new start and quality of life \\
\hline Diagnosis experienced as a relief & Experienced community \\
\hline Enough time for diagnosis & Trust, confidence, and feeling of worth \\
\hline Diagnosis and following up & Spiritual experiences \\
\hline The experience that service is available & Peer support and network \\
\hline Access to hospital & Welfare/socio-economic help \\
\hline \multirow[t]{2}{*}{ Hospital as a place of refuge in crisis } & Practical help \\
\hline & Housing and activities \\
\hline $\begin{array}{l}\text { Psychiatric-medical help experienced as } \\
\text { threatening and humiliating }(n=225)\end{array}$ & $\begin{array}{l}\text { Rejection and encroachment in therapeutic } \\
\text { relations with a humanistic-existential } \\
\text { psychosocial approach }(n=70)\end{array}$ \\
\hline \multicolumn{2}{|l|}{$\begin{array}{l}\text { Experienced rejection and isolation in } \\
\text { treatment context }\end{array}$} \\
\hline Not taken seriously & Bad communication \\
\hline Rejection, lack of treatment & Miscommunication \\
\hline Just stored away, no following up & No understanding \\
\hline Strain caused by treatment & Client's dilemma rejected \\
\hline Medicines abruptly removed & Childhood/trauma rejected \\
\hline Negative side effects of medicines & Persuasion to divorce \\
\hline Wrong diagnosis & $\begin{array}{l}\text { Children not cared about when parents were } \\
\text { sent to hospital/received help }\end{array}$ \\
\hline Disrespect and threat to integrity & Unethical behavior from the therapist \\
\hline Compulsion, punishment & Inappropriate behavior from the therapist \\
\hline Treated violently & Appointments not respected \\
\hline Accusations, infringements & \\
\hline
\end{tabular}

I had taken an overdose of medicines and was an in-patient at a local hospital. I made very good contact with a nurse there. She sat down at my bedside and talked to me. Gave me a good lotion after I had cut my arms with a broken piece of mirror and gave me the whole tube and a hug when I was sent to the psychiatric ward. I will never forget her! Woman, age 31.

To me the organisation MHN (Mental Health Norway) meant more than "the good helpers" I met in hospital 1.5 years ago. To experience fellowship and the feeling that you are doing something useful for others means quite a lot. Woman, age 45.

In the hospital I took part in body-oriented therapy. Then I got into contact with forgotten experiences from my childhood, experiences that my body remembered. It was a very painful experience and I needed years to heal the wounds. But this experience was a breakthrough in the effort to recover, and many questions were answered. Woman, age 54.

The narratives contain several plots describing relations between being labelled as a psychiatric patient and various kinds of rejections. The meaning dimension appeared when the clients were given the opportunity to present their own coherent stories about what had happened:

The chief physician wanted to give me $16 \mathrm{mg}$ Trilafon. My experience told me that I then would be totally unable to think. $8 \mathrm{mg}$ was enough to get me on my feet again. Then I was medicated by force, held by 4-5 persons while I got an injection in my buttocks. Gradually they discovered that I did not resist. Because I was also sexually abused as a child this was a horrible experience that still causes me to shiver as I write it down. It was good to have the opportunity to write about it. Man, aged 50.

5.2. The Confirmation of Identity. Narrative properties like efforts to confirm or protect identity and also to give rational reasons for the way of acting are clearly projecting in this material, but in addition some extra dimensions related to the confirmation of identity were discovered; the expressions of disempowerment and the unusual strong efforts to confirm identity and justify oneself as a rational being are as follows. 
I was afraid and thought someone would kill me. I was prevented from talking to the doctor and locked myself into the bathroom. The water warmed and comforted me. They came in. I said: Do not touch me; I will go to my room. They did touch me. I got angry. I am sad I did not write this when I was angry and felt I was not listened to. I bit the woman who touch me and tore up her blouse. She got angry and wouldn't let me talk. I was awake the whole night because of anxiety. She reported how hopeless I was. I think she should have listened to me; maybe we could have avoided the episode in the bathroom if she had called the doctor. I did not trust her, that's the reason I could not tell her anything. When I locked the door to the bathroom I can understand that they maybe were worried about me, but it was not necessary to touch me, because I would have gone myself and, furthermore, I was in a humiliating situation there in the bathtub. I did pay for the blouse. Woman, age 62.

Most of the negative stories are reports about the lack of responsiveness, which invoke feelings of rejection as well as humiliation. Besides they illustrate that feedback from clients is neither necessarily welcomed nor used to improve the quality of the services.

To be taken care of, listened to, respected, and supported means that pain and suffering is made bearable and several informants reported that relations marked by these qualities helped them back to a normal life and even to a richer life than before.

For 13 years I had the help line number for the anxiety self-help organisation on my bulletin board. I did not dare to call. But then I decided that I had to. I called. After the talk I dared to visit them. When meeting the leader I for the first time experienced not to be alone with my bottomless shame. Other people had the same experiences. This happened one year ago and today I feel that life is opening up. Woman, age 44.

The need to confirm or reestablish identity seems to be of special importance when a client's dignity has been threatened or lost due to a humiliating process in the course of treatment. The disempowered client language and the efforts several informants spend on confirming identity emerge as the most interesting discoveries when looking for narrative plots in the clients' stories. An underlying message is about the need to reclaim dignity, which in turn means integration of the experience of lost honour $[27,28]$. Reshaping identity may involve a new kind of honesty meaning that there is no reason to pretend, thus being willing to reveal what has threatened the self-image and sense of dignity. A main question concerns the health service system's ability to understand the processes that represent a threat to the person's integrity and the implications of lost dignity.

It is a paradox that the experience of lost honour is often related to being a client in the health service system. Important information about the social order is embedded in this paradox. Stories about compassionate encounters marked by responsiveness, genuine care, and empathetic understanding do not have the same need of strong legitimating explanations.

After having fought with all kinds of bureaucracy and systems I at last considered committing suicide as a final escape. In desperation and by accident I passed a house where Catholic monks lived. I am not a Catholic, but was met with incredible warmth and not least, respect. The brother invited me inside and we talked until I felt able to walk home. Later we had several talks about thoughts I was struggling with. The brother's genuine wish to help showed through and he offered to engage himself also beyond the conversations. Until this day I have never met a person with an equivalent capacity to look into the soul and meet another person on this person's premise. I could also contact him whenever I wanted. This caused me to restrain myself, but I still experienced the feeling of security. Man, age 43.

The stories have illustrated the search for meaning as well as efforts to confirm identity. The composition of plots is an overall demonstration about rationally described connections between the users' earlier or recent experiences and their present situation and exemplifies the strong need of experiencing meaning and confirming identity. At the same time they inform on personal experiences and knowledge which can benefit the health service system if listened to and taken seriously.

The efforts to demonstrate rationality appeared as extra strong when the users described situations where their identity and honour were threatened. Very detailed descriptions about what happened and why tell about feelings of powerlessness or that understanding cannot be taken for granted. Situations of powerlessness and threatened identity also informed about a distance gap experienced between the way services were delivered and what the users themselves regarded as beneficial.

\section{Ethical Reasons for Recognising Clients' Stories as Coherent Knowledge}

Ethics concerns protecting dignity and respecting integrity and represents fundamental values in human relations. In research, these ethical principles should always be considered. Schaanning [29] has suggested that in a situation where we can no longer relate to a final truth as being the "last instance" ethics should take on the role of being this "last instance." Research will then be evaluated by its ability to facilitate the implementation of actions to the good, improve human conditions and preserve dignity, and empower patients to exercise increased control over their lives [30-32]. But in the field of mental health care ethical guidelines can also contribute to the silencing of clients' voices, as protection barriers are set up against discussing personal subjects with "vulnerable" persons [33]. This emerges as a paradox as there are no indications that mental health clients themselves want this special protection. In fact, being able to relate their tales of suffering could be a way for the person to find an opening to their inner worlds and interpretations of what has been experienced and thus serve an essential path towards its alleviation (cf. [34]). The mentioned ethical guidelines stem from a paternalistic attitude saying that vulnerability in this field may be related to lack of self-insight or ability to handle one's own emotions. So, ethical guidelines by themselves do not necessarily protect clients' interests, which further points to the importance of upholding clients' right to tell their stories and making dialogic communication a main ethical 
concern [35-37]. As underlined by Bachtin [38] dialogic communication is the essential realm of humans and "to deny the dialogue is to deny the human being" ([38]: 282).

Users' perspectives and users' choices have been on the agenda for some decades, but there have been unsaid reservations, as highlighted by Morrison et al. [39], asking, antipsychotics, is it time to introduce patient choice? As mental health services have for decades been dominated by the psychopharmacological "revolution," stigmatisation, and lack of response to clients' expressed needs can hardly be understood without observing the tradition which allows professionals to medicate clients without their free and informed consent [40]. To Barker and Buchanan-Barker [41] this concerns the major ethical dilemma, that is, autonomy versus paternalism in the field of mental health. They criticise the ethical literature for avoiding dilemmas raised by the use of coercion, for contributing to the confusion over the nature of "mental disorder," and for embracing the misplaced paternalism they see as part of the medical tradition. If there is a single psychiatric "truth" they say, "it is that people had a better chance of recovery from a psychiatric 'breakdown' before the advent of psychiatric drugs 60 years ago, than they do today" ([41]: 455, see also [42]). Given this knowledge the use of coercion as well as a nonresponsive attitude in general raises serious ethical questions concerning autonomy and lack of reciprocity in therapeutic settings. A disputable scientific fundament is not, according to human rights' legislation [43], able to justify the serious encroachments into peoples' lives we talk about here. The convention on the rights of people with disabilities [44] then takes further steps to transform mental health users' status according to ethical standards, by among others underlining legal capacity as a universal property (art 12) and the universal right to healthcare including being on the basis of free and informed consent (art 25). Ethical reasons then also have become legal reasons, which will support the process of implementing ethical standards related to the recognition of clients' voices.

\section{Epistemological Tensions in the Field of Mental Health Care}

Users' own stories have challenged the history of psychiatry and also become assimilated into it so that tensions between users' and professionals' understandings are partly transformed into tensions between two different professional and epistemological approaches where roughly spoken the first one sees the evolution of psychiatry as associated with progress made in biomedicine while the other contributes by reflecting about context and how society influences the development of mental illness and how we perceive it [3]. The division may be traced back to different sources. By the writings of Foucault [45], Scheff [46], and Goffman [47] the ideological aspects behind all historical analyses became visible and also the relations between broader social trends like social disciplining, regulations, division of labour, definitions of deviation, and stigma processes on one hand and how we define and handle mental disabilities on the other hand. In philosophy and psychology a new concept of
Self originated as studies into rationality and consciousness revealed human beings as less rational and with a less stable Self than presumed earlier $[29,48]$. This new concept of Self also contributed to changed attitudes about madness and influenced treatment institutions. Both critical approaches advocating contextual understanding and new insights into human beings' limited rationality seem to have strengthened the arguments for listening to the "voices from below" and confirmed patients' right to possess their own clinical experience [3].

Along with controversies over the rationality of human beings in general, the dispute between professional approaches concerning mental patients' lack of selfinsight still goes on. Even if attempts at defining the insight phenomenon are scarce $[49,50]$, information about the opinions and experiences of mental health clients is lost to a greater degree compared to information obtained from other groups of clients, which may be explained by the fact that the voice of the client is often seen as less valid because he/she is receiving mental health care [51].

In the postpsychiatry movement, it seems like clients' perspectives emerge as a critical element without denying traditional psychiatry as a science [52]. Maybe this movement can bridge the gap between the two approaches. But looking at the different ways psychoses are understood: as from outside, as biological defects which can be objectified, independent of the individual, or as a phenomenon anchored in fundamental human conditions and something that should be understood from inside, in the light of the subject's own experiences $[53,54]$, the bridge is not easily discovered.

Psychoses seen as pure irrationality sustain the impression that mental health clients lack self-insight to a larger degree than other groups of clients. In order to have clients' experiences accepted as coherent knowledge in their own right, it seems important to accept the need of reciprocity and trust that the dialogue can be reestablished also in situations of confusion and seemingly irrationality.

\section{Conclusion}

The clients' narratives emerge as coherent and with obvious plots and are also often marked by less typical characteristics like the very strong efforts to confirm identity and demonstrate rationality and sometimes a kind of honesty or selfexposure which can best be understood in relation to a need of integrating the experience of lost honour. The common factor is the need to, and the importance of, being recognized as a subject. Several narratives-by illustrating the lack of responsiveness-repeatedly demonstrate the existence of a gap between users' and professionals' discourses. A main reason seems to be a hegemonic, professional discourse creating distance to users' own experiences and counteracting equal dialogues. Users' voices are still to a large degree silenced by an objectifying epistemology. Thereby the health services are also deprived of information that would be essential for planning, management, and further improvements in the field of mental health care. 


\section{Ethical Approval}

The project was registered at the Norwegian Social Science Database (NSD) which has delegated authority from the Data Inspectorate of Norway to accept investigations in which sensitive, personal information is involved. The collecting of data organised in such a way that the researchers were unable to identify the informants. In practice the user organisation had ownership of the investigation and asked its own members to participate.

\section{Conflict of Interests}

The authors declare that there is no conflict of interests regarding the publication of this paper.

\section{References}

[1] R. Porter, A Social History of Madness. Stories of the Insane, Weidenfeld and Nicholson, London, UK, 1987.

[2] A. J. W. Andersen and I. B. Larsen, "Hell on earth: textual reflections on the experience of mental illness," Journal of Mental Health, vol. 21, no. 2, pp. 174-181, 2012.

[3] R. Huertas, "Another history for another psychiatry. The patient's view," Culture \& History, vol. 2, no. 1, 2013.

[4] G. Lefevbre, Les Payans Du Nord Pendant La Revolution Francaise, C. Robbe, Lille, France, 1924.

[5] A. Molinari, "Autobiografias de mujeres en un manicomio italiano a principios del siglo XX," in Letras Bajo Sospecha. Escritura y Lectura en Centros de Internamiento, A. Castillo, V. Sierra, and G. Trea, Eds., pp. 79-96, 2005.

[6] B. Williams and G. Grant, "Defining people-centredness: making the implicit explicit," Health and Social Care in the Community, vol. 6, no. 2, pp. 84-94, 1998.

[7] T. A. Andreassen, User Involvement, Policy and the Welfare State. Dr. Polit Dissertation [Ph.D. thesis], Institute of Sociology and Social Geography, University of Oslo, 2004.

[8] Health Directorate of Norway, User Involvement in Mental Health Care. Objectives, Recommendations and Actions, The Norwegian Directorate of Health, 2006.

[9] P. Beresford and A. Wilson, "Genes spell danger: mental health service users/survivors, bioethics and control," Disability \& Society, vol. 17, no. 5, pp. 541-553, 2002.

[10] T. A. Andreassen, "When users are not taken seriously," Journal of Welfare Research, vol. 10, no. 1, pp. 3-14, 2007.

[11] P. Barker, Assessment in Psychiatric and Mental Health Nursing. In Search of the Whole Person, Stanley Thornes, Cheltenham, UK, 1997.

[12] R. Kogstad, Stories from other positions [Ph.D. thesis], Faculty of Medicine, University of Oslo, 2011.

[13] J. K. Hummelvoll and A. B. da Silva, "The use of the qualitative research interview to uncover the essence of community psychiatric nursing: methodological reflections," Journal of Holistic Nursing, vol. 16, no. 4, pp. 453-478, 1998.

[14] H. Starks and S. B. Trinidad, "Choose your method: a comparison of phenomenology, discourse analysis, and grounded theory," Qualitative Health Research, vol. 17, no. 10, pp. 13721380, 2007.

[15] A. Jaworski and N. Coupland, "Introduction: perspectives on discourse analysis," in The Discourse Reader, A. Jaworski and N.
Coupland, Eds., Taylor \& Francis Group, Routledge, New York, NY, USA, 2nd edition, 2006.

[16] L. C. Hydén, “The numerous stories," in To Study Narratives, L. C. Hydén and M. Hydén, Eds., Liber AB, Stockholm, Sweden, 1997.

[17] D. Edwards, "Narrative analysis," in The Discourse Reader, A. Jaworski and N. Coupland, Eds., Taylor \& Francis, Routledge, New York, NY, USA, 2nd edition, 2006.

[18] E. G. Mishler, Research Interviewing: Context and Narrative, Harvard University Press, Cambridge, Mass, USA, 1986.

[19] D. E. Polkinghorne, Narrative Knowing and the Human Sciences, State University of New York, New York, NY, USA, 1988.

[20] U. H. Graneheim and B. Lundman, "Qualitative content analysis in nursing research: concepts, procedures and measures to achieve trustworthiness," Nurse Education Today, vol. 24, no. 2, pp. 105-112, 2004.

[21] R. E. Kogstad, J. K. Hummelvoll, and B. G. Eriksson, "User experiences of different treatment cultures in mental health care," Ethical Human Psychology and Psychiatry, vol. 11, no. 2, pp. 97-111, 2009.

[22] A. Giddens, New Rules of Sociological Method: A Positive Critique of Interpretative Sociologies, Stanford University Press, 1993.

[23] C. Mattingly and L. C. Garro, Narrative and the Cultural Construction of Illness and Healing, Berkeley University of California Press, 2000.

[24] J. Lacan, The Symbolic, Selected Drafts, By Svein Haugsgjerd, Gyldendal, Oslo, Norway, 1985.

[25] L. J. Kirmayer, "Healing and the invention of metaphor: the effectiveness of symbols revisited," Culture, Medicine and Psychiatry, vol. 17, no. 2, pp. 161-195, 1993.

[26] U. Wikan, "With life on one's lap," in Narrative and the Cultural Construction of Health and Illness, C. Mattingly and L. Garro, Eds., Berkeley University of California Press, 2000.

[27] P. Deegan, "Recovery as a journey of the heart," in Recovery from Severe Mental Illnesses: Research Evidence and Implications for Practice, L. Davidson, C. Harding, and L. Spaniol, Eds., Center for Psychiatric Rehabilitation, Boston University, 2005.

[28] S. J. Onken, C. M. Craig, P. Ridgway, R. O. Ralph, and J. A. Cook, "An analysis of the definitions and elements of recovery: a review of the literature," Psychiatric Rehabilitation Journal, vol. 31, no. 1, pp. 9-22, 2007.

[29] E. Schaanning, Dissolving Modernity, Spartacus, Oslo, Norway, 1992.

[30] Y. S. Lincoln and E. Guba, Naturalistic Inquiry, Sage, Beverly Hills, Calif, USA, 1985.

[31] S. Kvale, InterViews. An Introduction To Qualitative Research Inquiry, Sage, Thousand Oaks, Calif, USA, 1996.

[32] M. W. Jørgensen and L. Philips, Discourse Analysis as Theory and Method, Roskilde Universitetsforlag, 1999.

[33] J. K. Hummelvoll, "Forskningsetikk i handlingsorientert forskningssamarbeid med mennesker med psykiske problemer," in Etiske Utfordringer i Praksisnoer Forskning, J. K. Hummelvoll, E. Andvig, and A. Lyberg, Eds., Gyldendal Akademisk, Oslo, Norway, 2010.

[34] M. Arman and A. Rehnsfeldt, "How can we research human suffering?" Scandinavian Journal of Caring Sciences, vol. 20, no. 3, pp. 239-240, 2006.

[35] E. Levinas, The Other's Humanism, Thorleif Dahl's Cultural Library, Aschehoug, Oslo, Norway, 1993. 
[36] I. B. Neumann, "Meaning, materiality and power," in An Introduction To Discourse Analysis, Fagbokforlaget, Bergen, Norway, 2001.

[37] A. Johnsen, R. Sundet, and V. W. Torsteinsson, Interaction and Self Experience. New Ways in Relation Oriented Therapies, Tano Aschehoug, Oslo, Norway, 2000.

[38] M. Bachtin, The Dialogic Word, Bokfirlaget Anthropos AB, Graabo, Sweden, 1997.

[39] A. P. Morrison, P. Hutton, D. Shiers, and D. Turkington, "Antipsychotics: is it time to introduce patient choice?" The British Journal of Psychiatry, vol. 201, pp. 83-84, 2012.

[40] P. Tyrer, "From the editor's desk, The end of the psychopharmacological revolution," British Journal of Psychiatry, vol. 201, article 168, 2012.

[41] P. Barker and P. Buchnan-Barker, "First, do no harm: confronting the myths of psychiatric drugs," Nursing Ethics, vol. 19, no. 4, pp. 451-463, 2012.

[42] D. Healy, M. Harris, P. Michael et al., "Service utilization in 1896 and 1996: morbidity and mortality data from North Wales," History of Psychiatry, vol. 16, no. 1, pp. 27-41, 2005.

[43] ECHR (European Convention on Human Rights), Council of Europe, 1950.

[44] "CRPD (Convention on the Rights of Persons with Disabilities)," Adopted by the United Nation's General Assembly on December 2006.

[45] M. Foucault, History of Madness in the Classical Age, Translated by: J. Khalfa \& J. Murphy, First Published 1961, Routledge, 2006.

[46] T. J. Scheff, Being Mentally Ill: A Sociology Theory, Aldine, Chicago, Ill, USA, 1966.

[47] E. Goffman, Asylums, Doubleday, New York, NY, USA, 1961.

[48] D. Kaufmann, Aufklärung, Selbsterfahrung und Die Erfindung der Psychiatrie in Deutschland, 1770-1850, Vandenhoeck \& Ruprecht, Göttingen, Germany, 1995.

[49] G. Høyer, "On the justification for civil commitment," Acta Psychiatrica Scandinavica, Supplement, vol. 101, no. 399, pp. 6571, 2000.

[50] T. Grisso and P. S. Appelbaum, "Structuring the debate about ethical predictions of future violence," Law and Human Behavior, vol. 17, no. 4, pp. 482-485, 1993.

[51] B. Williams, "Users' views of community mental health care," in Community Care: Evaluation of the Provision of Mental Health Services, C. Crosby and M. M. Barry, Eds., Brookfield, Avebury, UK, 1995.

[52] P. Bracken and P. Thomas, "Postpsychiatry: a new direction for mental health," British Medical Journal, vol. 322, no. 7288, pp. 724-727, 2001.

[53] T.-J. Ekeland, "Ny kunnskap—ny praksis. Et nytt psykisk helsevern," Erfaringskompetanse, nr. 1, 2011.

[54] T.-J. Ekeland, “Kampen om kunnskapen,” Morgenbladet, 2013. 


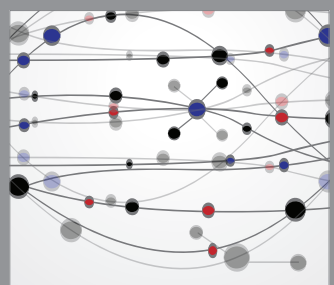

The Scientific World Journal
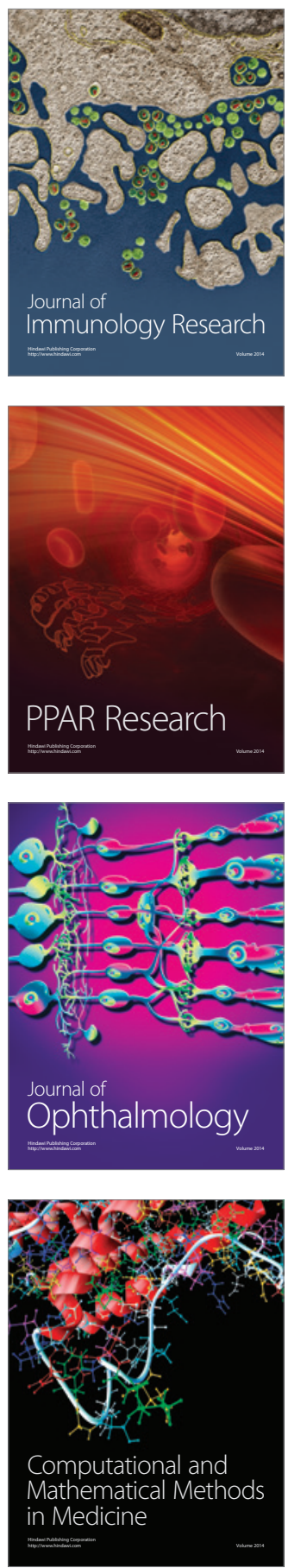

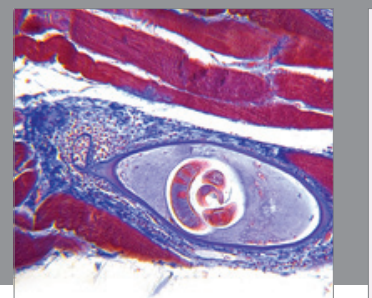

Gastroenterology

Research and Practice
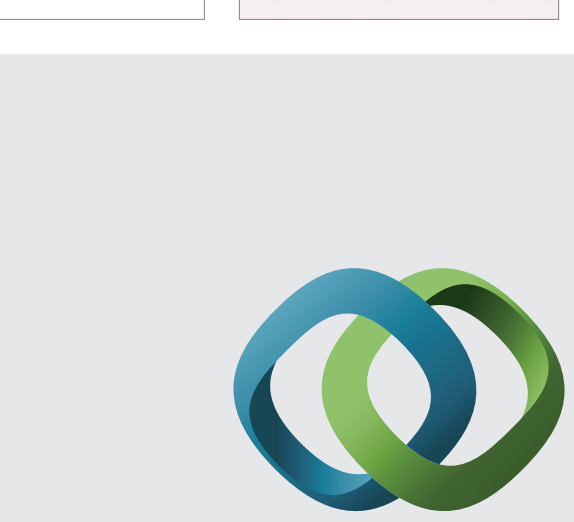

\section{Hindawi}

Submit your manuscripts at

http://www.hindawi.com
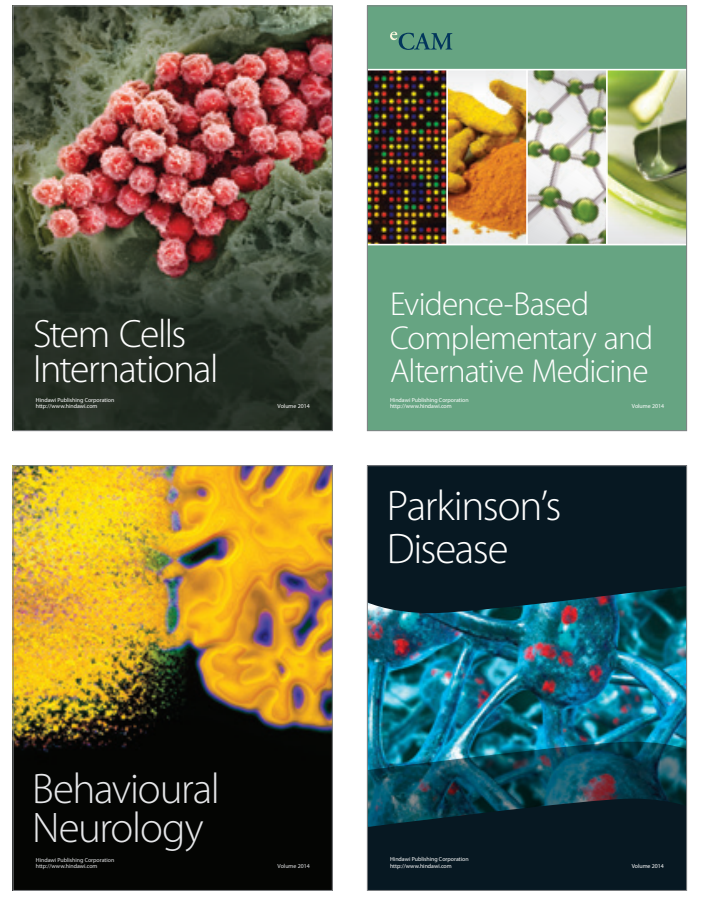
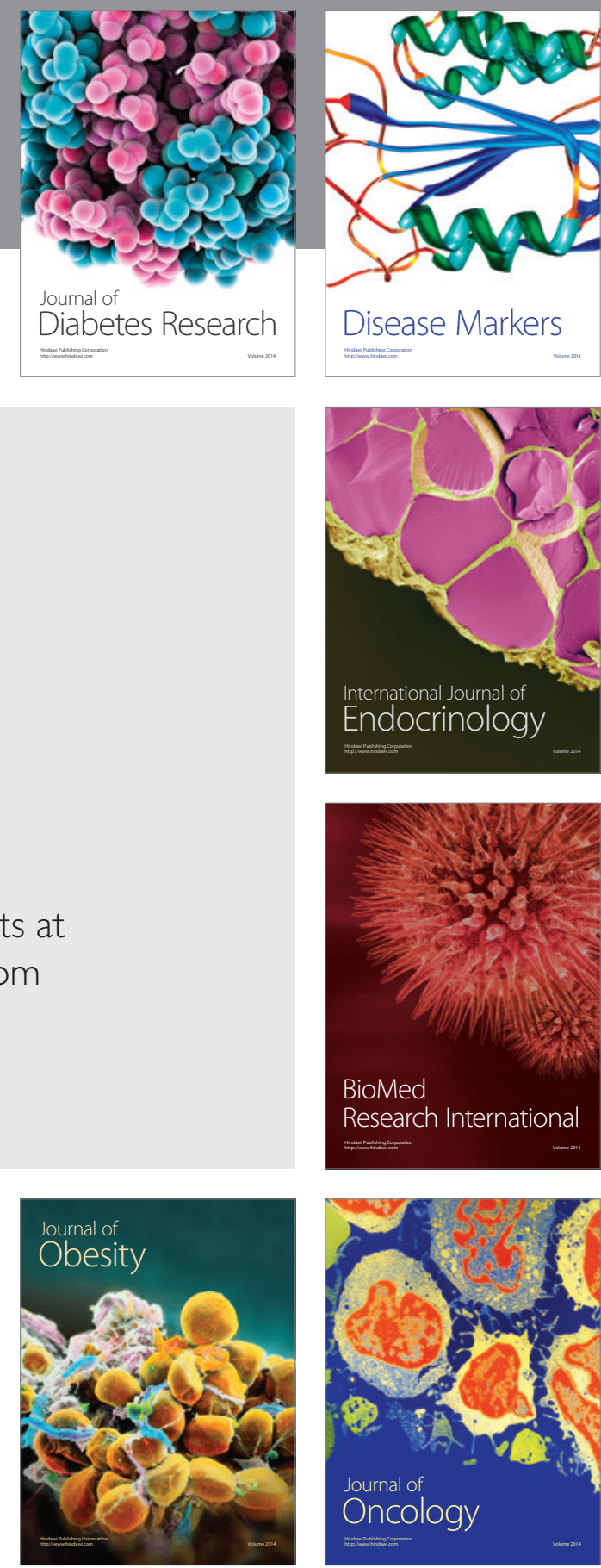

Disease Markers
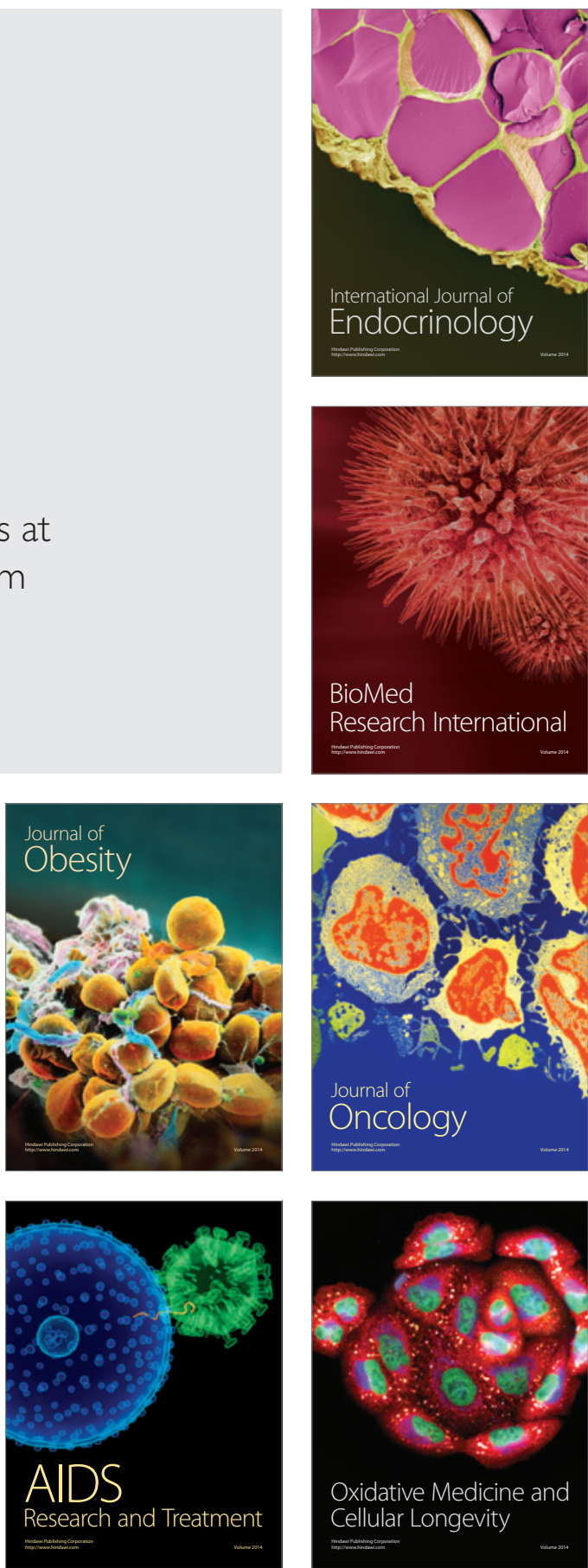